\title{
Does Obesity Affect the Severity of Exercise-Induced Muscle Injury?
}

\author{
Jooyoung Kim', Jin Hwan Yoon²,* \\ 'Office of Academic Affairs, Konkuk University, Chungju; ${ }^{2}$ Department of Sport Science, College of Life Science and Nano Technology, Hannam University, Daejeon, \\ Korea
}

This literature review investigates the effects of obesity on exercise-induced muscle injury and reexamines the potential mechanisms of exercise-induced muscle injury related to obesity. Several studies reported that high body mass index and percent body fat can significantly affect the markers of muscle injury after exercise, including maximal strength, delayed onset muscle soreness, creatinine kinase level, and myoglobin level. The potential mechanisms resulting in these outcomes include structural changes in the cell membrane induced by high fat levels, increased inflammatory responses due to adipose tissues, reduced muscle satellite cell activation and myogenesis due to lipid overload, differences in muscle fiber distributions, and sedentary behaviors. These mechanisms, however, must be verified through more research. As obesity is a potential risk factor increasing the severity of exercise-induced muscle injuries, the exercise intensity and duration for obese patients must be carefully selected, and a preconditioning intervention (e.g., low-intensity eccentric training) may be considered before or during the early stages of the exercise program.

Key words: Adipose tissue, Body mass index, Creatine kinase, Exercise, Inflammation, Obesity

Received September 21, 2020

Reviewed November 21, 2020

Accepted January 2, 2021

${ }^{*}$ Corresponding author

Jin Hwan Yoon

(i)

https://orcid.org/0000-0001-9026-6416

Department of Sport Science, College of Life Science and Nano Technology, Hannam University, 70 Hannam-ro, Daedeok-gu, Daejeon 34430, Korea Tel: +82-42-629-7990

Fax: +82-42-629-8402

E-mail:yoonjh@hnu.kr

\section{INTRODUCTION}

Obesity is a disease that has become an important issue worldwide and in health-related policies. ${ }^{1}$ Regular participation in exercise is an important component of an obesity treatment program ${ }^{2}$ and significantly improves the body composition by reducing weight and body fat while increasing lean body mass; therefore, it has been known to effectively prevent hypertension, type 2 diabetes, metabolic syndrome, and cardiovascular diseases. ${ }^{3-5}$

However, exercising at an intensity beyond one's physical abilities or performing unaccustomed exercises that involve eccentric muscle contractions has been reported to induce muscle injuries. ${ }^{6,7}$ Muscle injuries reduce muscle function and significantly increase not only the leakage of proteins such as creatinine kinase $(\mathrm{CK})$ and myoglobin $(\mathrm{Mb})$ into the bloodstream, but also the activation lev- els of cells associated with inflammatory responses. ${ }^{8,9}$ Furthermore, they induce delayed onset muscle soreness (DOMS), which hinders recovery, interferes with regular exercise, and negatively affects one's psychological health..$^{10-12}$

Several studies have reported that the higher the levels of the body composition markers such as body mass index (BMI) and percent body fat (\%BF), the more severe the muscle injury after eccentric exercise and the more delayed the recovery. ${ }^{13-16} \mathrm{Kim}$ and $\mathrm{So}^{14}$ reported that individuals with a high BMI had greater loss of maximal strength and increase in the severity of DOMS and CK levels after eccentric exercise. Margaritelis et al. ${ }^{16}$ also reported that a group with high $\% \mathrm{BF}$ had greater reduction in muscle function and increase in DOMS and CK levels after eccentric exercise than did a group with lower \%BF.

While studies on obesity and exercise have mostly focused on

Copyright @ 2021 Korean Society for the Study of Obesity

(a) This is an Open Access article distributed under the terms of the Creative Commons Attribution Non-Commercial License (https://creativecommons.org/licenses/by-nc/4.o/) which permits unrestricted non-commercial use, distribution, and reproduction in any medium, provided the original work is properly cited. 
changes in body composition and physical fitness, limited studies have been conducted on muscle injuries that occur after exercise in patients with obesity. Therefore, this literature review investigates the effects of obesity on exercise-induced muscle injuries by examining previous research and re-examining the potential mechanisms of exercise-induced muscle injuries related to obesity.

\section{EXERCISE-INDUCED MUSCLE INJURY}

As previously explained, suddenly engaging in intense or unaccustomed exercise after a long period of physical inactivity and performing exercises that involve eccentric muscle contractions can lead to muscle injuries. ${ }^{6}$ Eccentric muscle contraction is one of many types of muscle contractions that form body movements. It refers to contractions in which the activated muscle lengthens and is a major cause of exercise-induced muscle injuries. ${ }^{17}$ Linnamo et al. ${ }^{18}$ and Morgan et al. ${ }^{19}$ reported that eccentric muscle contractions do not occur completely during the recruitment of muscle fibers for maximal strength during exercise and are thus more likely to cause muscle injury than isotonic or isometric muscle contractions.

In general, the mechanisms of exercise-induced muscle injuries are divided into primary and secondary muscle damages. Primary muscle damage refers to the morphological changes caused by muscle length changes and muscle tension. Proske and Morgan ${ }^{20}$ reported that sarcomere lengths exceed the normal range of contraction during an eccentric muscle contraction, and the resulting tension causes muscle injury. Repeated eccentric muscle contractions lead to sarcomere injuries, including those of the Z-disk, I band, and A band that result in "Z-disk streaming." ${ }^{20}$ Furthermore, Lomonosova et al. ${ }^{21}$ and Raastad et al. $^{22}$ reported that additional injuries can occur not only in the sarcolemma and sarcoplasmic reticulum but also in cytoskeletal elements such as desmin, dystrophin, vimentin, nestin, and lamin.

The causes of secondary muscle damage, which occurs after primary muscle damage, include loss of homeostasis of calcium ions and increased inflammatory responses and oxidative stress. Murphy and Lamb ${ }^{23}$ and Vissing et al. ${ }^{24}$ reported that without the reuptake of calcium ions released to the cytosol back into the sarcoplasmic reticulum by Ca-ATPase, excitation-contraction coupling, which induces muscle contraction, becomes impaired, thus leading to the activation of calpain, a $\mathrm{Ca}^{2+}$-dependent protease, and elevated inflammatory responses in the injured muscle. Peake et al. ${ }^{25}$ reported that the activities of neutrophils and macrophages, which are leukocytes, increase in the event of a muscle injury. Neutrophils contribute to increasing the risk of muscle injury by secreting chemoattractants that promote phagocytosis and proinflammatory cytokines. ${ }^{26}$ Proinflammatory cytokines additionally activate the production of substrates that are toxic to neutrophils and generate free radicals that induce oxidative stress. ${ }^{27}$

Macrophages are divided into M1 and M2, playing complex roles in inflammatory responses. M1 macrophages are abundant in necrotic muscle fibers one day after neutrophil infiltration and are activated by proinflammatory cytokines such as tumor necrosis factor- $\alpha$ (TNF- $\alpha$ ) and interleukin (IL) $-1 \beta \cdot{ }^{28}$ Activated M1 macrophages produce and release more than 100 different substrates, including prostaglandin and proinflammatory cytokines, to strengthen the inflammatory response. ${ }^{29}$ On the other hand, M2 macrophages are observed after inflammatory responses and mediate tissue repair and growth by increasing the levels of growth-promoting factors, including fibroblast growth factor, insulin-like growth factor 1, transforming growth factor- $\beta 1$, and cytokines. ${ }^{30}$

\section{EFFECT OF OBESITY ON EXERCISE-INDUCED MUSCLE INJURY}

Several studies have reported that obesity can affect the markers associated with exercise-induced muscle injury. ${ }^{14,15,31-33}$ Salvadori et al. ${ }^{32}$ performed an exercise test in 10 healthy subjects with a mean BMI of $22 \mathrm{~kg} / \mathrm{m}^{2}$ and 11 obese patients with a mean BMI of 41 $\mathrm{kg} / \mathrm{m}^{2}$ using a cycle ergometer and reported that the obese patients showed higher increases in CK levels than did the healthy subjects. Paschalis et al..$^{33}$ divided 22 healthy women into a lean group (BMI, $18.5-24.9 \mathrm{~kg} / \mathrm{m}^{2}$; mean BMI, $\left.21.2 \mathrm{~kg} / \mathrm{m}^{2}\right)$ and an overweight group (BMI, $25.0-33.0 \mathrm{~kg} / \mathrm{m}^{2}$; mean BMI, $29.5 \mathrm{~kg} / \mathrm{m}^{2}$ ) and instructed them to perform eccentric exercise of the knee extensor using an isokinetic dynamometer. In comparison of the muscle injury markers between the two groups, the authors ${ }^{33}$ found a greater reduction in muscle torque and greater DOMS during palpation and walking in the overweight group than in the lean group. The overweight group also showed significantly higher CK levels from 
24 to 72 hours after exercise than the lean group.

Paschalis et al. ${ }^{34}$ reported similar results in their study in 2013. They divided 32 healthy women into two groups according to BMI to perform eccentric exercise. They reported that the overweight group with a high BMI (mean BMI, $29.4 \mathrm{~kg} / \mathrm{m}^{2}$ ) showed negative changes in the parameters associated with muscle function and had increased DOMS and CK levels compared with the lean group with a normal BMI (mean BMI, $22.0 \mathrm{~kg} / \mathrm{m}^{2}$ ). Kim and So ${ }^{14}$ divided 40 healthy male university students into a normal BMI (18.5$\left.22.9 \mathrm{~kg} / \mathrm{m}^{2}\right)$ group and a high BMI $\left(\geq 25 \mathrm{~kg} / \mathrm{m}^{2}\right)$ group to perform eccentric exercise of the elbow flexor using a modified preacher curl machine. They observed significant changes in the maximal isometric strength, DOMS, and CK levels after eccentric exercise in both groups. However, the high BMI group showed a higher reduction in maximal isometric strength immediately after exercise than did the normal BMI group and showed a delayed recovery throughout the whole period after the exercise (Fig. 1). The high BMI group also showed higher DOMS severity (Fig. 2) and CK levels.

On the other hand, Comstock et al. ${ }^{31}$ reported that BMI does not affect post-exercise muscle injury. They divided 19 healthy males into groups according to BMI and instructed them to perform acute resistance exercise. They reported no significant changes in the levels of CK or Mb, or DOMS severity according to BMI. However, the examined muscle injury markers and their measurement timings in Comstock's study ${ }^{31}$ differed from those in previous studies. ${ }^{14,33}$ For instance, the mean CK level was $\geq 1,000 \mathrm{U} / \mathrm{L}$ after

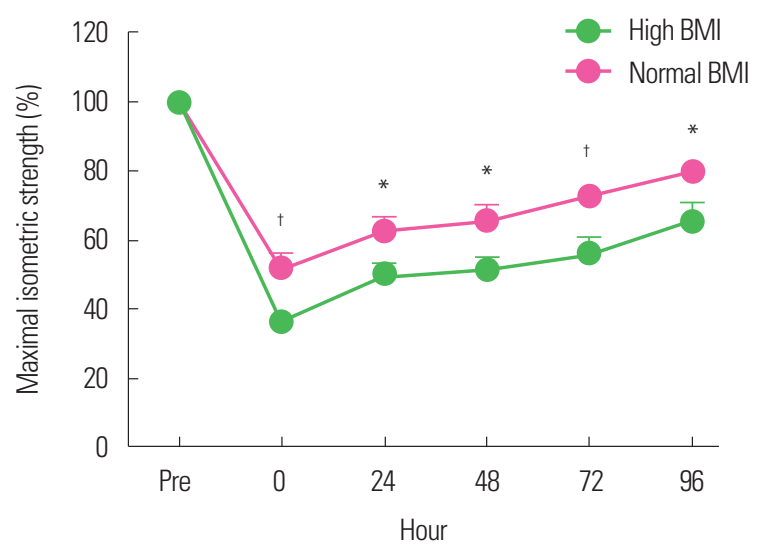

Figure 1. Change of maximal isometric strength after eccentric exercise according to body mass index (BMI). Normal BMl, 18.5-22.9 kg/m²; high BMl, $\geq 25 \mathrm{~kg} / \mathrm{m}^{2}$. *Significant difference between groups $(P<0.05)$; ${ }^{\dagger}$ Significant between group $(P<0.01)$. Data from Kim and So. ${ }^{14}$ exercise in both the high BMI and lean groups in the studies by Kim and So ${ }^{14}$ and Paschalis et al., ${ }^{33}$ whereas the mean CK level was $188 \mathrm{U} / \mathrm{L}$ in the high BMI $\left(>35 \mathrm{~kg} / \mathrm{m}^{2}\right.$ ) group and $195.8 \mathrm{U} / \mathrm{L}$ in the lean (BMI, $\left.<25 \mathrm{~kg} / \mathrm{m}^{2}\right)$ group at 24 hours after exercise, without any significant difference as compared with the baseline value in the study by Comstock et al. ${ }^{31}$ These CK results may indirectly indicate that the resistance exercise assigned to the subjects did not sufficiently induce muscle injury. Furthermore, because Comstock et al. ${ }^{31}$ only measured muscle injury markers until 24 hours after exercise, the changes in these markers that occurred after the 24 hours could not be determined. Studies on exercise-induced muscle injury generally measure changes in muscle injury markers until 96 hours after exercise. ${ }^{35,36}$

In their recent study that used an eccentric exercise protocol for the elbow flexor similar to the one used by Kim and So, ${ }^{14}$ Yoon and $\mathrm{Kim}^{15}$ reported that while BMI can be used to make a simple diagnosis of obesity, it does not accurately represent the amount of adipose tissues; thus, they examined the association between \%BF and muscle injury. They divided 30 healthy male university students into a high $\% \mathrm{BF}(\geq 20 \%)$ group and a low $\% \mathrm{BF}(\leq 15 \%)$ group according to their $\% \mathrm{BF}$ and instructed them to perform high-intensity eccentric exercise. They reported that the high \%BF group showed high $\mathrm{CK}$ and $\mathrm{Mb}$ levels during the post-exercise recovery period as compared with the low \%BF group (Fig. 3). These results were similar to those of Margaritelis et al., ${ }^{16}$ who induced muscle injury in 39 healthy women by subjecting them to knee extensor exercise

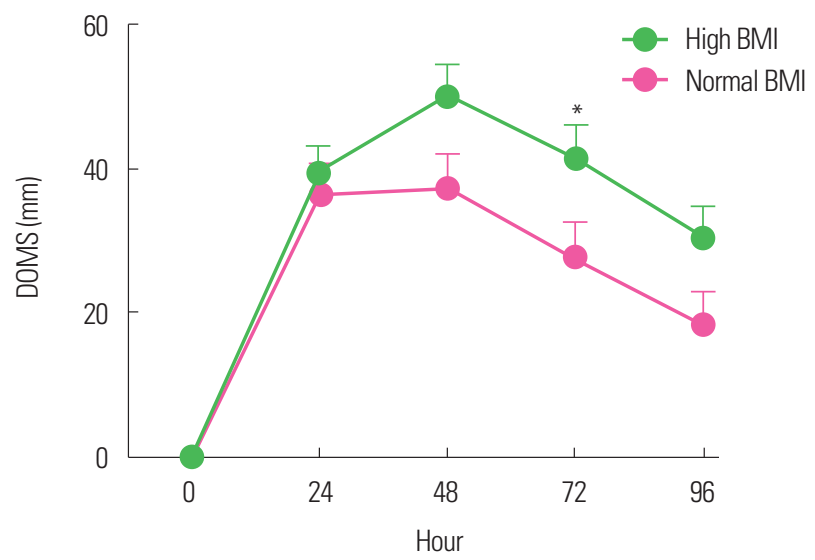

Figure 2. Change of delayed onset muscle soreness (DOMS) after eccentric exercise according to body mass index (BMI). Normal BMI, 18.5-22.9 kg/m²; high BMI, $\geq 25 \mathrm{~kg} / \mathrm{m}^{2}$. ${ }^{*}$ Significant difference between groups $(P<0.05)$. Data from Kim and So. ${ }^{14}$ 

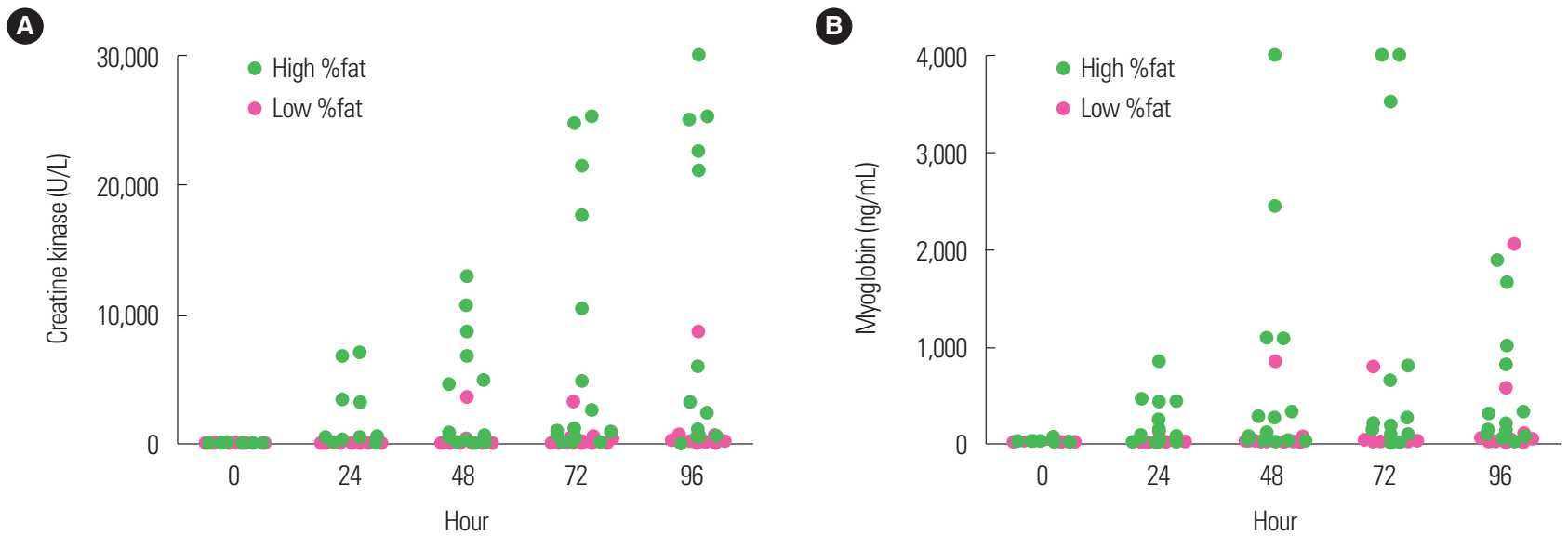

Figure 3. Change of creatine kinase (A) and myoglobin (B) after eccentric exercise according to body fat percentage (\%fat). High \%fat, $\geq 20 \%$; low \%fat, $\leq 15 \%$. Data from Yoon and Kim. ${ }^{15}$

using an isokinetic dynamometer and reported that the overweight group with a $\% \mathrm{BF} \geq 30.1 \%$ had higher $\mathrm{CK}$ levels than did the lean group.

The increased $\mathrm{CK}$ and $\mathrm{Mb}$ levels observed in the studies by Yoon and $\mathrm{Kim}^{15}$ and Margaritelis et al. ${ }^{16}$ are an indirect indication of muscle membrane disruption after exercise. ${ }^{37}$ In relation to this, Knoblauch et al. ${ }^{38}$ reported that obese mice showed a greater myofiber membrane disruption after downhill running as an eccentric exercise than did lean mice, suggesting that obese mice are more susceptible to mechanical injury. Although these results were obtained from an animal experiment, they allow visualization of the morphological changes of injured myofibers after eccentric exercise on light microscopy, which are the direct evidence of the changes in $\mathrm{CK}$ and $\mathrm{Mb}$ levels after eccentric exercise. In contrast, Totsuka et al..$^{39}$ divided 15 young males into a high responder group (CK level, $>500 \mathrm{IU}$ ) and a low responder group (CK level, < $300 \mathrm{IU}$ ) according to the $\mathrm{CK}$ level after endurance exercise and reported that \%BF had no effect on the CK level in both groups. However, the two groups had \%BF of $15.6 \%$ and $17.4 \%$, respectively, and did not comprise obese participants.

\section{POTENTIAL MECHANISMS RELATED TO EXERCISE-INDUCED MUSCLE INJURY AND OBESITY}

Obesity refers to the excessive lipid accumulation in adipose or non-adipose tissues (e.g., skeletal muscle $)^{40}$ and can cause structural changes in the cell membrane, making it vulnerable to mechanical tension. ${ }^{38} \mathrm{~A}$ few studies reported that high levels of fat cause the saturation of fatty acyl chains in the sarcolemma to increase the phospholipid packing density and membrane rigidity. ${ }^{41-43}$ Such structural changes may aggravate cell membrane disruption in response to a mechanical stimulus from exercise, consequently increasing the $\mathrm{CK}$ and $\mathrm{Mb}$ levels.

As obesity increases, the levels of circulating inflammatory molecules and macrophage cell infiltration via the effect of proinflammatory cytokines released from adipose tissues, it can cause chronic low-grade inflammation. ${ }^{44}$ The M1 macrophages of macrophage cells exhibit proinflammatory characteristics that are more activated by high fat levels. ${ }^{45}$ Therefore, obesity-induced increases in inflammatory responses and $\mathrm{M} 1$ macrophages in injured muscles can promote cell membrane disruption (Fig. 4).

A few studies reported the association between inflammatory responses and cell membrane disruption. ${ }^{36,46}$ Kanda et al. ${ }^{36}$ examined changes in various inflammation markers after eccentric exercise and reported that increased levels of neutrophil migratory activity after exercise are positively correlated with changes in $\mathrm{Mb}$ levels. Kawamura et al. ${ }^{46}$ reported that increased IL- 6 concentration after eccentric exercise significantly correlated with the peripheral neutrophil count and serum CK activity. Dutra et al. ${ }^{47}$ and Tajra et al. ${ }^{48}$ provided evidence suggesting that obesity affects cell membrane disruption after exercise. Dutra et al. ${ }^{47}$ reported that excess body fat is associated with increased levels of inflammatory markers such as IL-7 and C-reactive protein levels in postmenopausal women. Tajra 


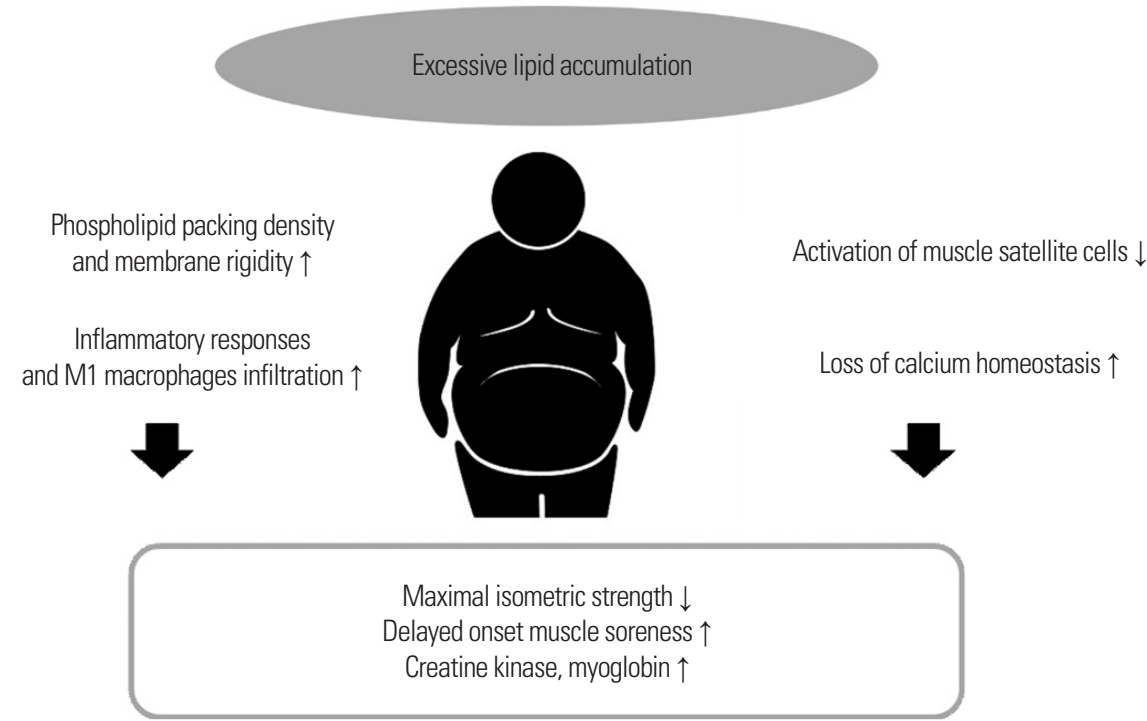

Figure 4. Potential mechanisms related to exercise-induced muscle injury and obesity.

et al. ${ }^{48}$ reported high CK levels in the recovery period in elderly obese women with high IL-6 levels after exercise.

Obesity-induced inflammatory responses are highly likely to contribute to the increase in post-exercise DOMS severity. Although the causes of DOMS are unclear, a major hypothesis suggests inflammatory responses as one cause., ${ }^{9,49}$ Increased levels of bradykinin and prostaglandin during inflammatory response can stimulate types III and IV afferent nerve fibers near the muscle, thus inducing DOMS. ${ }^{9} \mathrm{~A}$ few studies ${ }^{50,51}$ reported that body fat is associated with musculoskeletal pain and suggested that the upregulation of cytokines (TNF- $\alpha$ ) secreted by adipose tissues and the resulting systemic inflammation may be involved in this association.

However, further research on the relationship between obesity and post-exercise DOMS is needed. While a few studies reported higher DOMS severity levels in obese individuals after performing eccentric exercise, ${ }^{14,33}$ they did not directly measure inflammation markers. Miles et al. ${ }^{52,53}$ reported that obesity-induced increases in the levels of inflammation markers are not associated with DOMS. Miles et al. ${ }^{52}$ divided subjects into a normal-weight (BMI, $\leq 25 \mathrm{~kg} / \mathrm{m}^{2}$; mean BMI, $22.4 \mathrm{~kg} / \mathrm{m}^{2}$ ) group and an overweight (BMI, 25-30 $\mathrm{kg} / \mathrm{m}^{2}$; mean BMI, $27.1 \mathrm{~kg} / \mathrm{m}^{2}$ ) group and instructed them to perform eccentric exercise of the elbow flexor using an isokinetic dynamometer. They reported higher levels of sTNFR1 and IL-6 at $12-24$ hours and 8 hours after exercise, respectively, in the over- weight group than in the normal-weight group, but no significant difference in DOMS between the two groups. In their study in 2016, Miles et al..$^{53}$ divided subjects into a low waist circumference (Lo-WC; $\leq 80 \mathrm{~cm}$ ) group and a high waist circumference (Hi-WC; $>80 \mathrm{~cm}$ ) group according to waist circumference, which is a marker of abdominal obesity, and examined changes in the markers of muscle injury after downhill or uphill running exercise. They reported higher IL-6 levels during the recovery period in the Hi-WC group than in the Lo-WC group regardless of the type of exercise but no significant difference in DOMS between the two groups. The reason for the conflicting results of the studies is unclear, and further research is necessary to draw a clear conclusion.

A study reported that lipid overload disrupts the activation of muscle satellite cells, thereby reducing myogenesis. ${ }^{54}$ Regeneration after muscle injury requires the activation of muscle stem and satellite cells..$^{55}$ Satellite cells are called the stem cells of muscles and exist between the sarcolemma and basement membrane of terminally differentiated muscle fibers. ${ }^{56}$ They usually stay dormant but induce myogenesis through activation, proliferation, differentiation, and fusion in the event of a muscle injury. ${ }^{57}$ However, increases in insulin or leptin resistance and levels of proinflammatory cytokines in individuals with obesity disrupt satellite cell proliferation and, subsequently, myogenesis. ${ }^{58}$ Based on these facts, an obesity-induced reduction in satellite cell activation and myo- 
genesis may delay the recovery of muscle functions, such as maximal isometric strength, after the onset of an exercise-induced muscle injury. However, most studies that examined the relationship between obesity and myogenesis were animal studies and did not use exercise to induce muscle injury. Thus, additional studies must be conducted.

Researchers have proposed the loss of calcium homeostasis, differences in muscle fiber distributions, and sedentary behavior as the potential mechanisms by which obesity increases the severity of exercise-induced muscle injury. As obesity causes oxidative stress by inducing excessive production of reactive oxygen species, it can interfere with the functioning of sarcoplasmic reticulum $\mathrm{Ca}^{2+}$-ATPase and calcium signaling, thereby reducing muscle contractions. ${ }^{59}$ In addition, individuals with obesity have an increased type IIb muscle fiber distribution and are thus susceptible to muscle injury. They have low levels of physical activity and sedentary lifestyles and, therefore, require more high force actions during exercise than lean individuals. ${ }^{33}$ However, further research is needed to clearly verify the mechanisms.

\section{CONCLUSION}

Several studies have identified obesity as a factor that can potentially increase the severity of exercise-induced muscle injury. Therefore, an exercise prescription must be carefully designed to allow sufficient time for adaptation to the assigned exercise intensity in the early phases of exercise and post-exercise recovery in obese patients. Preconditioning intervention, such as low-intensity eccentric training, must be considered before or during the early phases of an exercise program that involves many eccentric muscle contractions. Future studies must reveal the mechanisms associated with postexercise muscle injury in individuals with obesity more clearly and investigate the effects of various interventions that reduce the risk of post-exercise muscle injury and promote recovery in individuals with obesity.

\section{CONFLICTS OF INTEREST}

Jin Hwan Yoon is the Editorial Board member of the Journal of Obesity \& Metabolic Syndrome. However, he is not involved in the peer reviewer selection, evaluation, or decision process of this article. Otherwise, no other potential conflicts of interest relevant to this article were reported.

\section{AUTHOR CONTRIBUTIONS}

Study concept and design: JK, JHY; drafting of the manuscript: JK, JHY; critical revision of the manuscript: JHY.

\section{REFERENCES}

1. Wirth A, Wabitsch M, Hauner H. The prevention and treatment of obesity. Dtsch Arztebl Int 2014;111:705-13.

2. Okay DM, Jackson PV, Marcinkiewicz M, Papino MN. Exercise and obesity. Prim Care 2009;36:379-93.

3. Fonseca-Junior SJ, Sá CG, Rodrigues PA, Oliveira AJ, Fernandes-Filho J. Physical exercise and morbid obesity: a systematic review. Arq Bras Cir Dig 2013;26 Suppl 1:67-73.

4. Machado AP, Lima BM, Laureano MG, Silva PH, Tardin GP, Reis PS, et al. Educational strategies for the prevention of diabetes, hypertension, and obesity. Rev Assoc Med Bras (1992) 2016;62:800-8.

5. O'Gorman DJ, Krook A. Exercise and the treatment of diabetes and obesity. Med Clin North Am 2011;95:953-69.

6. Paulsen G, Mikkelsen UR, Raastad T, Peake JM. Leucocytes, cytokines and satellite cells: what role do they play in muscle damage and regeneration following eccentric exercise? Exerc Immunol Rev 2012;18:42-97.

7. Peake JM, Neubauer O, Della Gatta PA, Nosaka K. Muscle damage and inflammation during recovery from exercise. J Appl Physiol (1985) 2017;122:559-70.

8. Park J, Lee S, Kim S, Song J, Kwak H, Kang J, et al. Physical performance and inflammation responses during and after the jiu-jitsu stimulated match according to recovery treatment methods. Exerc Sci 2020;29:214-24.

9. Hyldahl RD, Hubal MJ. Lengthening our perspective: morphological, cellular, and molecular responses to eccentric exercise. Muscle Nerve 2014;49:155-70.

10. Kim C, Sun M, Kim M. Cardiac autonomic responses and adaptation to repeated bouts of eccentric exercise. Exerc Sci 
2020;29:359-67.

11. Kim J, Lee J. A review of nutritional intervention on delayed onset muscle soreness: part I. J Exerc Rehabil 2014;10:349-56.

12. Serinken MA, Gençoğlu C, Kayatekin BM. The effect of eccentric exercise-induced delayed-onset muscle soreness on positioning sense and shooting percentage in wheelchair basketball players. Balkan Med J 2013;30:382-6.

13. Hickner RC, Mehta PM, Dyck D, Devita P, Houmard JA, Koves $\mathrm{T}$, et al. Relationship between fat-to-fat-free mass ratio and decrements in leg strength after downhill running. J Appl Physiol (1985) 2001;90:1334-41.

14. Kim J, So WY. High body mass index is associated with the extent of muscle damage after eccentric exercise. Int J Environ Res Public Health 2018;15:1378.

15. Yoon EJ, Kim J. Effect of body fat percentage on muscle damage induced by high-intensity eccentric exercise. Int J Environ Res Public Health 2020;17:3476.

16. Margaritelis NV, Theodorou AA, Kyparos A, Nikolaidis MG, Paschalis V. Effect of body composition on redox homeostasis at rest and in response to exercise: the case of underfat women. J Sports Sci 2019;37:1630-7.

17. Newton MJ, Morgan GT, Sacco P, Chapman DW, Nosaka K. Comparison of responses to strenuous eccentric exercise of the elbow flexors between resistance-trained and untrained men. J Strength Cond Res 2008;22:597-607.

18. Linnamo V, Bottas R, Komi PV. Force and EMG power spectrum during and after eccentric and concentric fatigue. J Electromyogr Kinesiol 2000;10:293-300.

19. Morgan DL, Gregory JE, Proske U. The influence of fatigue on damage from eccentric contractions in the gastrocnemius muscle of the cat. J Physiol 2004;561(Pt 3):841-50.

20. Proske U, Morgan DL. Muscle damage from eccentric exercise: mechanism, mechanical signs, adaptation and clinical applications. J Physiol 2001;537(Pt 2):333-45.

21. Lomonosova IuN, Zhelezniakova AV, Bugrova AE, Zhiriakova AV, Kalamkarov GR, Nemirovskaia TL. Protective effect of nitric oxide on cytoskeletal proteins in skeletal muscles under eccentric exercise. Biofizika 2009;54:515-21.

22. Raastad T, Owe SG, Paulsen G, Enns D, Overgaard K, Crameri $\mathrm{R}$, et al. Changes in calpain activity, muscle structure, and function after eccentric exercise. Med Sci Sports Exerc 2010;42:86-95.

23. Murphy RM, Lamb GD. Calpain-3 is activated following eccentric exercise. J Appl Physiol (1985) 2009;106:2068.

24. Vissing K, Overgaard K, Nedergaard A, Fredsted A, Schjerling P. Effects of concentric and repeated eccentric exercise on muscle damage and calpain-calpastatin gene expression in human skeletal muscle. Eur J Appl Physiol 2008;103:323-32.

25. Peake J, Nosaka K, Suzuki K. Characterization of inflammatory responses to eccentric exercise in humans. Exerc Immunol Rev 2005;11:64-85.

26. Toumi H, F'guyer S, Best TM. The role of neutrophils in injury and repair following muscle stretch. J Anat 2006;208: 459-70.

27. Best TM, Fiebig R, Corr DT, Brickson S, Ji L. Free radical activity, antioxidant enzyme, and glutathione changes with muscle stretch injury in rabbits. J Appl Physiol (1985) 1999;87: 74-82.

28. Butterfield TA, Best TM, Merrick MA. The dual roles of neutrophils and macrophages in inflammation: a critical balance between tissue damage and repair. J Athl Train 2006;41: 457-65.

29. Scott A, Khan KM, Roberts CR, Cook JL, Duronio V. What do we mean by the term "inflammation"? A contemporary basic science update for sports medicine. Br J Sports Med 2004;38:372-80.

30. Tidball JG. Mechanisms of muscle injury, repair, and regeneration. Compr Physiol 2011;1:2029-62.

31. Comstock BA, Thomas GA, Dunn-Lewis C, Volek JS, Szivak TK, Hooper DR, et al. Effects of acute resistance exercise on muscle damage and perceptual measures between men who are lean and obese. J Strength Cond Res 2013;27:3488-94.

32. Salvadori A, Fanari P, Ruga S, Brunani A, Longhini E. Creatine kinase and creatine kinase-MB isoenzyme during and after exercise testing in normal and obese young people. Chest 1992;102:1687-9.

33. Paschalis V, Nikolaidis MG, Giakas G, Theodorou AA, Sakellariou GK, Fatouros IG, et al. Beneficial changes in energy expenditure and lipid profile after eccentric exercise in overweight and lean women. Scand J Med Sci Sports 2010;20: 
e103-11.

34. Paschalis V, Nikolaidis MG, Theodorou AA, Deli CK, Raso V, Jamurtas AZ, et al. The effects of eccentric exercise on muscle function and proprioception of individuals being overweight and underweight. J Strength Cond Res 2013;27:2542-51.

35. Jakeman JR, Lambrick DM, Wooley B, Babraj JA, Faulkner JA. Effect of an acute dose of omega-3 fish oil following exercise-induced muscle damage. Eur J Appl Physiol 2017;117: 575-82.

36. Kanda K, Sugama K, Hayashida H, Sakuma J, Kawakami Y, Miura S, et al. Eccentric exercise-induced delayed-onset muscle soreness and changes in markers of muscle damage and inflammation. Exerc Immunol Rev 2013;19:72-85.

37. Clarkson PM, Hoffman EP, Zambraski E, Gordish-Dressman H, Kearns A, Hubal M, et al. ACTN3 and MLCK genotype associations with exertional muscle damage. J Appl Physiol (1985) 2005;99:564-9.

38. Knoblauch MA, O’Connor DP, Clarke MS. Obese mice incur greater myofiber membrane disruption in response to mechanical load compared with lean mice. Obesity (Silver Spring) 2013;21:135-43.

39. Totsuka M, Nakaji S, Suzuki K, Sugawara K, Sato K. Break point of serum creatine kinase release after endurance exercise. J Appl Physiol (1985) 2002;93:1280-6.

40. Unger RH, Clark GO, Scherer PE, Orci L. Lipid homeostasis, lipotoxicity and the metabolic syndrome. Biochim Biophys Acta 2010;1801:209-14.

41. Andersson A, Nälsén C, Tengblad S, Vessby B. Fatty acid composition of skeletal muscle reflects dietary fat composition in humans. Am J Clin Nutr 2002;76:1222-9.

42. McMurchie EJ, Patten GS, McLennan PL, Charnock JS, Nestel PJ. The influence of dietary lipid supplementation on cardiac beta-adrenergic receptor adenylate cyclase activity in the marmoset monkey. Biochim Biophys Acta 1988;937:347-58.

43. Pollock AH, Tedla N, Hancock SE, Cornely R, Mitchell TW, Yang Z, et al. Prolonged intake of dietary lipids alters membrane structure and T cell responses in LDLr-/- Mice. J Immunol 2016;196:3993-4002.

44. Cancello R, Clément K. Is obesity an inflammatory illness? Role of low-grade inflammation and macrophage infiltration in human white adipose tissue. BJOG 2006;113:1141-7.

45. Luo W, Ai L, Wang B, Wang L, Gan Y, Liu C, et al. Eccentric exercise and dietary restriction inhibits M1 macrophage polarization activated by high-fat diet-induced obesity. Life Sci 2020;243:117246.

46. Kawamura T, Suzuki K, Takahashi M, Tomari M, Hara R, Gando Y, et al. Involvement of neutrophil dynamics and function in exercise-induced muscle damage and delayed-onset muscle soreness: effect of hydrogen bath. Antioxidants (Basel) 2018;7:127.

47. Dutra MT, Avelar BP, Souza VC, Bottaro M, Oliveira RJ, Nóbrega OT, et al. Relationship between sarcopenic obesity-related phenotypes and inflammatory markers in postmenopausal women. Clin Physiol Funct Imaging 2017;37:205-10.

48. Tajra V, Tibana RA, Vieira DC, de Farias DL, Teixeira TG, Funghetto SS, et al. Identification of high responders for interleukin- 6 and creatine kinase following acute eccentric resistance exercise in elderly obese women. J Sci Med Sport 2014; $17: 662-6$.

49. Connolly DA, Sayers SP, McHugh MP. Treatment and prevention of delayed onset muscle soreness. J Strength Cond Res 2003;17:197-208.

50. Sommer C, Kress M. Recent findings on how proinflammatory cytokines cause pain: peripheral mechanisms in inflammatory and neuropathic hyperalgesia. Neurosci Lett 2004; 361:184-7.

51. Walsh TP, Arnold JB, Evans AM, Yaxley A, Damarell RA, Shanahan EM. The association between body fat and musculoskeletal pain: a systematic review and meta-analysis. BMC Musculoskelet Disord 2018;19:233.

52. Miles MP, Keller JM, Kordick LK, Kidd JR. Basal, circadian, and acute inflammation in normal versus overweight men. Med Sci Sports Exerc 2012;44:2290-8.

53. Miles MP, Horrigan LC, Jay SE, Brown KM, Porter JW, Steward AN. Concentric and eccentric exercise, glycemic responses to a postexercise meal, and inflammation in women with high versus low waist circumference. Appl Physiol Nutr Metab 2016;41:1262-70.

54. D’Souza DM, Trajcevski KE, Al-Sajee D, Wang DC, Thomas M, Anderson JE, et al. Diet-induced obesity impairs muscle 
satellite cell activation and muscle repair through alterations in hepatocyte growth factor signaling. Physiol Rep 2015;3: e12506.

55. Yin H, Price F, Rudnicki MA. Satellite cells and the muscle stem cell niche. Physiol Rev 2013;93:23-67.

56. Morgan JE, Partridge TA. Muscle satellite cells. Int J Biochem Cell Biol 2003;35:1151-6.

57. Dumont NA, Bentzinger CF, Sincennes MC, Rudnicki MA.
Satellite cells and skeletal muscle regeneration. Compr Physiol 2015;5:1027-59.

58. Akhmedov D, Berdeaux R. The effects of obesity on skeletal muscle regeneration. Front Physiol. 2013;4:371.

59. Tallis J, James RS, Seebacher F. The effects of obesity on skeletal muscle contractile function. J Exp Biol 2018;221(Pt 13): jeb163840. 